\title{
Modified assay procedure for enhanced sensitivity of in vitro glutamine synthetase (GS) activity measurements in marine phytoplankton
}

\author{
John R. Clayton, Jr. ${ }^{1}{ }^{*}$ \& Saiyed I. Ahmed ${ }^{2}$ \\ ${ }^{1}$ School of Fisheries, WH-10, and ${ }^{2}$ School of Oceanography, WB-10, University of Washington, Seattle, Washington 98195, USA
}

\begin{abstract}
Glutamine synthetase (GS) is a key enzyme in the assimilation of combined inorganic nitrogen in marine microalgae. Consequently, the development of a sensitive assay technique for GS measurements can have important applications for studies of nitrogen metabolism in both laboratory cultures and field populations of phytoplankton. Bressler \& Ahmed (1984) have documented an in vitro assay technique for measurements of biosynthetic GS activity in a variety of marine phytoplankton species. To enhance the general applicability of this procedure, several modifications have been made to increase both the detection capability for the inorganic phosphate end product $\left(\mathrm{P}_{1}\right)$ and the recovery of total enzyme activity from phytoplankton samples. These improvements have resulted in an approximate 50 -fold increase in the overall detection capability for the enzyme, and should accelerate the interest in the use of this enzyme as a sensitive tool in physiological and ecological studies.
\end{abstract}

\section{INTRODUCTION}

Primary productivity in phytoplankton is a function of biochemical processes that ultimately incorporate extracellular nutrients into biomass. Since enzymes mediate these processes, the availability of sensitive assay techniques for measurements of key enzymatic steps involved in nutrient utilization can be of great utility in attempts to understand nutrient-related ecological processes in aquatic environments. For example, nutrient nitrogen is often present at extremely low concentrations in the euphotic zones of many marine ecosystems. Consequently, the importance of the utilization of combined inorganic nitrogen (nitrate, nitrite and ammonium) for primary productivity in these systems has fostered the development of sensitive in vitro assays for enzymes such as nitrate reductase (Eppley et al. 1969), nitrite reductase (Eppley \& Rogers 1970), glutamate dehydrogenase (Ahmed et al. 1977), and NADH-glutamate synthase (Clayton \& Ahmed 1986). Glutamine synthetase (GS) is an additional enzyme that is crucial for nitrogen assimilation processes in environments characterized by low ambient levels of nutrient nitrogen. GS cataly-

- Present address: Science Applications International Corp., 476 Prospect St., La Jolla, California 92037, USA zes the following reaction:

$$
\begin{aligned}
\text { L-glutamate }+ & \mathrm{NH}_{3}+\mathrm{ATP} \stackrel{\mathrm{GS}}{\longrightarrow} \\
\text { L-glutamine }+\mathrm{ADP} & +\mathrm{P}_{\mathrm{i}}+\mathrm{H}_{2} \mathrm{O}
\end{aligned}
$$

Measurements of the in vitro biosynthetic activity for GS have typically involved either spectrophotometric detection of the $\mathrm{P}_{\mathrm{i}}$ end product (e.g. Shapiro \& Stadtman 1970, Falkowski \& Rivkin 1976, Bressler \& Ahmed 1984) or detection of the ADP end product using a fluorometric coupled enzyme assay (Falkowski \& Rivkin 1976). Both approaches have limitations. The fluorometric coupled enzyme assay involves a rather complex reaction mixture containing substrates for not only the desired GS reaction but also the accompanying coupled enzyme reaction (e.g. pyruvate kinase, phosphoenolpyruvate, lactate dehydrogenase and $\mathrm{NADH}$ ). Although the alternative approach utilizing spectrophotometric measurement of $P_{i}$ does not require such elaborate reaction substrate mixtures, its usefulness has traditionally been limited by the relative insensitivity of the $P_{1}$ assay. Consequently, enhancement of the detection sensitivity for the end product $P_{1}$ in the biosynthetic GS assay would have significant practical importance for its application in both laboratory and field studies.

This paper summarizes efforts to achieve greater sensitivity for in vitro GS activity measurements in 
marine phytoplankton samples. Although similar to the parent method of Bressler \& Ahmed (1984), 2 modifications have been adopted to enhance overall assay sensitivity. First, a more sensitive method for detecting the end product inorganic phosphate $\left(\mathrm{P}_{1}\right)$ has been adapted to the procedure. Second, whole cell homogenates rather than cell-free extracts are used in the assay.

\section{METHODS AND MATERIALS}

Chemicals. All inorganic chemicals were reagent grade quality. The following organic chemicals were obtained from Sigma Chemical Co. (St. Louis, Missouri, USA): adenosine triphosphate (ATP), citrate, glutamate, imidazole and beta-mercaptoethanol. VWR Scientific Co. (Seattle, Washington, USA) was the source for malachite green (MG), ammonium molybdate $\left(\left[\mathrm{NH}_{4}^{+}\right]_{6} \mathrm{Mo}_{7} \mathrm{O}_{24} \cdot 4 \mathrm{H}_{2} \mathrm{O}\right.$, or $\left.\mathrm{AM}\right)$ and Sterox (St).

Algal cultures. The experimental organism used for tests in this paper was the marine diatom Skeletonema costatum (Grev.) Cleve (R. R. L. Guillard, 1956, Milford Harbor, Connecticut, USA). The isolate of this species was obtained from the Culture Collection of Marine Phytoplankton (CCMP), Bigelow Laboratory for Ocean Sciences, West Boothbay Harbor, Maine, USA (c/o Dr. R. R. L. Guillard). Batch cultures of the test organism were grown in autoclaved natural seawater (from Puget Sound, Washington, USA) that received sterile nutrient additions at concentrations specified in Harrison et al. (1980). The cultures were maintained in constant temperature water baths at $16.5^{\circ} \mathrm{C}$. Continuous light (i.e. $24 \mathrm{~h} \mathrm{~d}^{-1}$ ) at an intensity of 0.68 to $0.70 \times$ $10^{16}$ quanta $\mathrm{cm}^{-2} \mathrm{~s}^{-1}$ was provided by cool white fluorescent bulbs through a blue plexiglas sheet (Rohm and Haas \# 2069) (Harrison et al. 1977).

In vitro enzyme assay procedures using cell-free extracts and whole cell homogenates. The preparation of cell-free extracts from experimental phytoplankton cultures is described in Bressler \& Ahmed (1984). Briefly, a volume of phytoplankton culture was filtered onto a glass fiber filter. The filter was then homogenized in cold extraction buffer and centrifuged at $20400 \times \mathrm{g}$ for $10 \mathrm{~min}$. The centrifuged supernate was the cell-free extract. Whole cell homogenates were prepared in an identical manner, except that the cellular debris and filter material were not removed by centrifugation.

The in vitro enzyme assays for cell-free extracts and whole cell homogenates were similar to those described for the 'biosynthetic assay' in Bressler \& Ahmed (1984), except for the following differences. All assays were terminated by the addition of $0.300 \mathrm{ml}$ of $3 \mathrm{M} \mathrm{HCl}$. Assay tubes containing whole cell homogenates were then processed in a desk-top centrifuge to remove cellular debris and filter material. The resulting supernates, as well as the solutions from the cellfree extract tubes, were analysed for $P_{1}$ content. To minimize the release of $P_{i}$ from residual ATP, all terminated reaction solutions were maintained in ice-water baths until the final addition of citrate. To account for $\mathrm{P}_{\mathrm{i}}$ in the final reaction solutions due to processes other than the GS reaction itself, GS activities were calculated from the differences in the $\mathrm{P}_{i}$ contents of paired reaction tubes containing plus and minus glutamate.

Malachite green $P_{i}$ detection technique. Instead of the phosphate measurement technique employed by Bressler \& Ahmed (1984), the method described in Lanzetta et al. (1979) was utilized for final determination of $P_{\imath}$ quantities in terminated enzyme reaction solutions. Preparation of the malachite green/ammonium molybdate/Sterox (MG/AM/St) solution and the general conduct of the $P_{1}$ assay are described in Lanzetta et al. (1979). Due to the high sensitivity of this technique, only a known volume fraction of the terminated enzyme reaction solutions $(0.150 \mathrm{ml}$ out of 0.860 ml) was routinely assayed for $\mathrm{P}_{1}$. Upon addition of the citrate reagent, terminated enzyme reaction solutions were transferred from the ice-water bath to a room temperature environment. Lanzetta et al. (1979) noted that the temporal stability of the developed colored reaction was enhanced by the addition of the citrate reagent. However, with the GS reaction substrate mixtures the absorbance values continued to increase slightly over time. Consequently, an exact time interval (30.0 min) between the addition of the citrate reagent and the reading of the absorbance value at $660 \times$ $10^{-9} \mathrm{~m}$ was applied to all sample and $P_{\mathrm{i}}$ standard assay tubes.

\section{RESULTS}

\section{Application of the malachite green $P_{i}$ detection technique to the GS assay solution}

In contrast to the malachite green $\mathrm{P}_{\mathrm{i}}$ assay proposed in this paper, Bressler \& Ahmed (1984) utilized a molybdate method for detection of the end product $\mathrm{P}_{\mathrm{i}}$. To compare relative sensitivities of the malachite green and molybdate assays, standard curves for $\mathrm{P}_{1}$ were generated in solutions of the complete GS assay substrate mixture plus the sample extraction buffer. Linear regression equations fitted to data for these standard curves are summarized in Table 1 . The resulting ratio of the regression coefficients $\left(b_{1} / b_{2}\right)$ shows that the malachite green assay is approximately 28 times more sensitive than the molybdate assay for $P_{1}$ detection. The high correlation coefficient with the malachite green assay also indicates that this $P_{i}$ measurement procedure can be performed with a high degree of precision. 
Table 1. Linear regression information for phosphate standard curves using the malachite green and molybdate assays. The linear regression equation has the form $y=b(x)+a$, where $y$ is blank-corrected absorbance units and $\mathrm{x}$ is $10^{-9}$ moles $\mathrm{P}_{1}$ assayed. Absorbance readings were taken at $660 \times 10^{-9}$ and $850 \times 10^{-9} \mathrm{~m}$ for the malachite green and molybdate assays, respectively. $\mathrm{n}$ : number of points used for a regression analysisi $_{i} r$ : correlation coefficient for the fitted regression line; $b_{1} / b_{2}$ : ratio of regression coefficients for malachite green to molybdate assay

\begin{tabular}{|cccccc|}
\hline \multicolumn{1}{c}{ Assay } & $\mathrm{n}$ & $\mathrm{r}$ & $\mathrm{a}$ & $\mathrm{b}$ & $\mathrm{b}_{1} / \mathrm{b}_{2}$ \\
\hline Malachite green & 12 & 0.99 & 0.032 & 0.023007 & \\
Molybdate & 12 & 1.00 & 0.012 & 0.000811 & 28.4 \\
\hline
\end{tabular}

\section{GS activity in cell-free extracts versus whole cell homogenates}

Bressler \& Ahmed (1984) used cell-free extracts in their GS assays. Two tests were performed to compare in vitro enzyme activities obtained with cell-free extracts and whole cell homogenates from the same exponentially growing ( $\mathrm{NH}_{4}^{+}$sufficient) batch culture of Skeletonema costatum. The results are summarized in Table 2. In each instance approximately twice as much activity was detected with whole cell homogenates.

Since the utilization of whole cell homogenates differed from the procedure employed in Bressler \& Ahmed (1984), tests were performed to confirm that in vitro reaction substrate levels were still at non-limiting concentrations in the whole cell homogenate assay. Assay tubes containing whole cell homogenate from an exponentially growing ( $\mathrm{NO}_{3}^{-}$-sufficient) batch culture of Skeletonema costatum were incubated for times ranging from 0 to $120 \mathrm{~min}$. As illustrated in Fig. 1 , no decrease in activity rate was observed over the entire duration of the incubations. The error bars for the individual data points in the figure also indicate the good precision obtained with the malachite green/ whole cell homogenate procedure.

Table 2. Skeletonema costatum. GS activities in cell-free extracts and whole cell homogenates. Values for GS activities are means with standard deviations in parentheses $(n=3)$. All activities are in units of $10^{-6}$ moles of $P_{1}$ produced (1 culture) ${ }^{-1} \mathrm{~min}^{-1}$. CFE: cell-free extract; whole: whole cell homogenate

\begin{tabular}{|c|c|c|c|}
\hline & \multicolumn{3}{|c|}{ GS activity } \\
\hline & CFE & Whole & CFE/whole \\
\hline Test \# 1 & $\begin{array}{r}0.0249 \\
( \pm 0.0027)\end{array}$ & $\begin{array}{c}0.0511 \\
( \pm 0.0246)\end{array}$ & $\begin{array}{c}0.49 \\
( \pm 0.24)\end{array}$ \\
\hline Test \# 2 & $\begin{array}{c}0.0161 \\
( \pm 0.0028)\end{array}$ & $\begin{array}{r}0.0318 \\
( \pm 0.0059)\end{array}$ & $\begin{array}{c}0.51 \\
( \pm 0.13)\end{array}$ \\
\hline
\end{tabular}

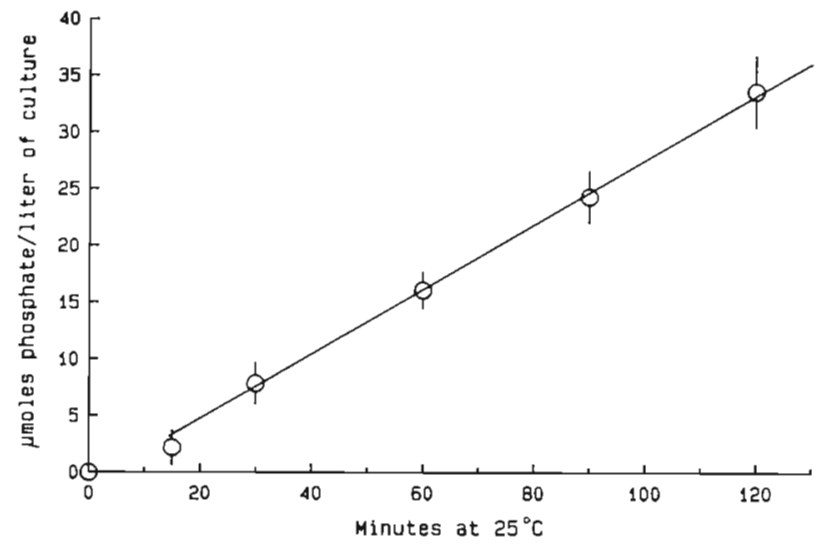

Fig. 1. Skeletonema costatum. In vitro GS activity levels with varying incubation times at $25^{\circ} \mathrm{C}$. GS activity is in units of $10^{-6}$ moles $P_{1}$ produced $1^{-1}$ of culture. Data points are mean values $(n=3)$ with \pm 1 standard deviation unit indicated by vertical bars. The linear regression line fitted to the data has the equation $y=0.284(x)-0.93(r=1.00)$

\section{Application of the procedure to field samples of phytoplankton}

Dortch et al. (1985) report efforts to measure GS activities in field samples of natural phytoplankton from Dabob Bay, Washington (USA). Activities were not detected in samples using the original method of Bressler \& Ahmed (1984) due to the relative 'insensitivity' of the assay. However, measurable levels of the enzyme were detected when the malachite green/ whole cell homogenate assay was applied to samples. For example, Fig. 2 presents a vertical profile of these GS activity measurements relative to the accompanying concentrations for total particulate nitrogen and chlorophyll a in the water column. The error bars included with the GS data in the figure again indicate the good precision obtained with the malachite green/ whole cell homogenate procedure. Although a more detailed presentation and discussion of this data is presented elsewhere (Dortch et al. 1985), the figure does illustrate a coupling between measured in vitro activity levels for the enzyme and accompanying biomass indicators (i.e. PN and chlorophyll a).

\section{DISCUSSION}

With the adoption of the malachite green $\mathrm{P}_{\mathrm{i}}$ detection technique and the use of whole cell homogenates, an approximate 50-fold increase in sensitivity for in vitro GS activity measurements is obtained. This enhanced sensitivity in still accompanied by a high degree of precision for replicate measurements. These modifications allow for detection and quantitation of 
a

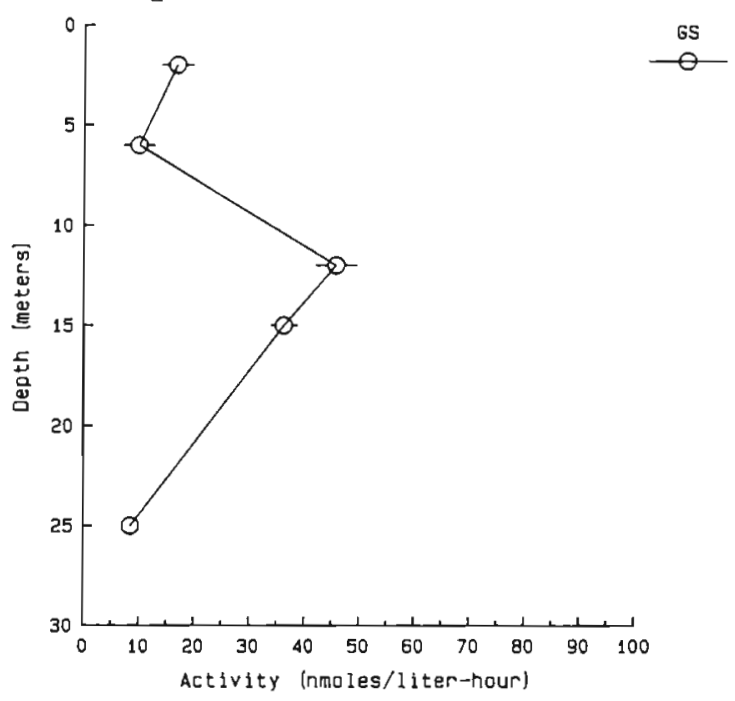

b

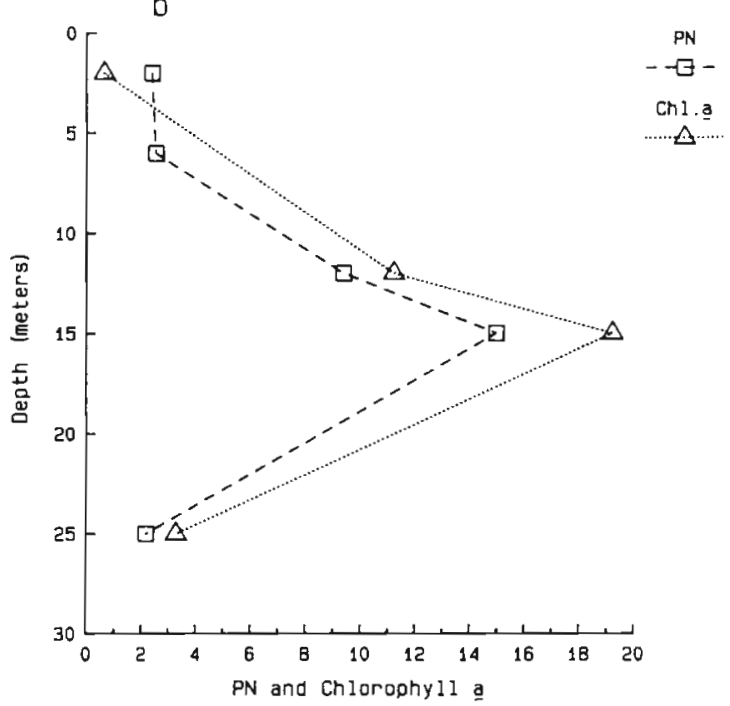

Fig. 2. Vertical profiles of (a) GS activity, and (b) PN and chiorophyli a concentrations from the water column in Dabob Bay, Washington (USA) on 8 Jul 1981. Data points for GS activities are mean values $(n=3)$ with \pm 1 standard deviation unit indicated by horizontal bars. Concentration units for PN and chlorophyll a are $10^{-6}$ moles $l^{-1}$ and $10^{-6} \mathrm{~g} \mathrm{I}^{-1}$ respectively. See Dortch et al.

(1985) for a more detailed discussion of the data

the GS enzyme in samples of much smaller size than those required with the method of Bressler \& Ahmed (1984). In addition to the advantages provided to studies with laboratory cultures of phytoplankton, this also has direct practical significance for measurements in field samples. Consequently, the modified GS assay has enhanced the sensitivity for the in vitro enzyme measurements to such an extent that even detectable field activity values are within the realm of possibility and practicality.

Acknowledgements. This research was supported by NSF Grants OCE 79-1959-1 and OCE 81-17937-2 awarded to Dr. S. I. Ahmed. This work was performed in partial fulfillment of the requirements for the degree of Doctor of Philosophy for John R. Clayton, Jr., School of Fisheries, University of Washington. We gratefully acknowledge Steven S. Thoresen for his constant assistance throughout these studies. We also appreciate the helpful comments of 4 unknown reviewers. Contribution No. 1683 from the School of Oceanography, University of Washington.

\section{LITERATURE CITED}

Ahmed, S. I., Kenner, R. A., Packard, T T (1977). A comparative study of the glutamate dehydrogenase activity in several species of marine phytoplankton. Mar. Biol. 39: 93-101

Bressler, S. L., Ahmed, S. I. (1984). Detection of glutamine synthetase activity in marine phytoplankton: optimization of the biosynthetic assay. Mar. Ecol. Prog. Ser. 14: 207-217

Clayton, J. R., Jr., Ahmed, S. I. (1986). Detection of glutamate synthase (GOGAT) activity in phytoplankton: evaluation of cofactors and assay optimization. Mar. Ecol. Prog. Ser. 32: 115-122

Dortch, Q., Clayton, J. R., Jr., Thoresen, S. S., Cleveland, J. S., Bressler, S. L., Ahmed, S. 1., (1985). Nitrogen storage and use of biochemical indices to assess nitrogen deficiency and growth rate in natural plankton populations. J. mar. Res. 43: 437-464

Eppley, R. W., Coatsworth, J. L., Solorzano, L. (1969). Studies of nitrate reductase in marine phytoplankton. Limnol. Oceanogr. 14: 194-205

Eppley, R. W., Rogers, J. N. (1970). Inorganic nitrogen assimilation of Ditylum brightwellii, a marine plankton diatom. J. Phycol. 6: 344-351

Falkowski, P. G., Rivkin, R. B. (1976). The role of glutamine synthetase in the incorporation of ammonium in Skeletonema costatum (Bacillariophyceae). J. Phycol. 12: 448-450

Harrison, P. J., Conway, H. L., Holmes, R. W., Davis, C. O. (1977). Marine diatoms grown in chemostats under silicate or ammonium limitation. III. Cellular chemical composition and morphology of Chaetoceros debilis, Skeletonema costatum, and Thalassiosira gravida. Mar Biol. 43: 19-31

Harrison, P. J., Waters, R. E., Taylor, F. J. R. (1980). A broad spectrum artificial seawater medium for coastal and open ocean phytoplankton. J. Phycol. 16: 28-35

Lanzetta, P. A., Alvarez, L. J., Reinach, P. S., Candia, O. A. (1979). An improved assay for nanomole amounts of inorganic phosphate. Analyt. Biochem. 100: 95-97

Shapiro, R. M., Stadtman, E. R. (1970). Glutamine synthetase (E. coll). In: Tabor, H., Tabor, C. W. (ed.) Methods in enzymology 17.A. Academic Press, New York, p. 910-922 